similar to a pacemaker pocket, was formed for the pump anterior to the right pectoralis major muscle. An incision was then made in the right fourth intercostal space to gain access to the left atrium through the Waterson groove. The nitinolreinforced silicone inflow cannula was inserted into the left atrium between the insertions of the right upper and lower pulmonary veins. The inflow cannula was tunneled through the second intercostal space to exit the thorax in the area of the subcutaneous pocket. The $8-\mathrm{mm}$ expanded polytetrafluoroethylene outflow graft was anastomosed to the subclavian artery. The electrical wire of the pump was then tunneled to exit the body over the right lower quadrant of the abdomen. Pump speed was set at 22,000 rpm (pump flow approximately $2.5 \mathrm{~L} / \mathrm{min}$ ), the surgical wounds were closed, and the patient was taken to the intensive care unit. The duration of the surgery was approximately 2 hours. Pump position is illustrated in Figure 1.

The patient recovered well from the surgery. Daily therapy was started with warfarin sodium (target international normalized ratio 2.5) and low-dose aspirin $(80 \mathrm{mg})$. The patient is currently ambulatory. He continues to improve his exercise capacity at home, makes visits, and climbs stairs. Table 1 summarizes the evolution of clinical parameters during the first 100 days after the procedure.

The patient had only minor complications. A hematoma developed at the subclavicular wound site on postoperative day 1 but had resolved by postoperative day 4 . Transient swelling developed in the right upper extremity on postoperative 4 but had resolved by postoperative day 7 .

\section{DISCUSSION}

We summarize here the first use of the Synergy MicroPump in a patient as a bridge to transplant. This device pro- vides partial left ventricular support $(2-3 \mathrm{~L} / \mathrm{min})$ and is specifically designed to be implanted in patients who are not as critically ill as the patients now typically receiving full support LVADs. Because of the small size of the device, the surgery was relatively short and significantly less traumatic than with other LVADs. The combination of the patient's intrinsic cardiac output of $3.6 \mathrm{~L} / \mathrm{min}$ with the $2.5 \mathrm{~L} / \mathrm{min}$ provided by the pump summed to a total cardiac output in excess of $6 \mathrm{~L} / \mathrm{min}$, a normal resting value. No significant hemolysis was noted, and there were no serious adverse effects.

There are several unique features of the device. This pump is the smallest implanted assist device ever used as a bridge to transplant. This is the first implanted device with the inflow cannula placed in the left atrium and the outflow cannula connected to the subclavian artery. Because of the unique anatomic position, the procedure was anticipated to be less invasive. As a result, flows of only $2.5 \mathrm{~L} / \mathrm{min}$ were able to produce clinically significant and sufficient acute hemodynamic effects.

\section{References}

1. Miller LW, Pagani FD, Russell SD, John R, Boyle AJ, Aaronson KD, et al. Use of a continuous-flow device in patients awaiting heart transplantation. $N$ Engl J Med. 2007;357:885-96.

2. Rogers JG, Butler J, Lansman SL, Gass A, Portner PM, Pasque MK, et al. Chronic mechanical circulatory support for inotrope-dependent heart failure patients who are not transplant candidates: results of the INTrEPID Trial. J Am Coll Cardiol. 2007;50:741-7.

3. Lietz K, Long JW, Kfoury AG, Slaughter MS, Silver MA, Milano CA, et al. Outcomes of left ventricular assist device implantation as destination therapy in the post-REMATCH era: implications for patient selection. Circulation. 2007; 116:497-505.

4. Deng MC, Edwards LB, Hertz MI, Rowe AW, Keck BM, Kormos R, et al. Mechanical circulatory support device database of the International Society for Heart and Lung Transplantation: third annual report-2005. J Heart Lung Transplant. 2005;24:1182-7.

\title{
A bilobed thoracic outlet mass: Options for resection
}

\author{
Glenn McKay, MD, ${ }^{a}$ Vincent Arlet, MD, ${ }^{\mathrm{b}}$ John A. Kern, MD, ${ }^{\mathrm{a}}$ Christine L. Lau, MD, ${ }^{\mathrm{a}}$ David R. Jones, MD, ${ }^{\mathrm{a}}$ and \\ Benjamin D. Kozower, MD, ${ }^{\text {a }}$ Charlottesville, Va
}

Complete resection of thoracic outlet tumors is challenging because of limited access and close proximity of vital neuro-

\footnotetext{
From the Divisions of Thoracic and Cardiovascular Surgery a and Orthopedic Surgery, ${ }^{\mathrm{b}}$ University of Virginia School of Medicine, Charlottesville, Va. Received for publication Dec 2, 2007; accepted for publication Dec 16, 2007.

Address for reprints: Benjamin D. Kozower, MD, University of Virginia Medical Centre, General Thoracic Surgery, PO Box 800679, Charlottesville, Virginia, VA 22908 (E-mail: bdk8g@virginia.edu).

J Thorac Cardiovasc Surg 2009;137:245-7

$0022-5223 / \$ 36.00$

Copyright (c) 2009 by The American Association for Thoracic Surgery

doi:10.1016/j.jtcvs.2007.12.041
}

vascular structures. We present a hemiclamshell approach with removal of the first rib to facilitate resection of a bilobed mass compressing the right subclavian artery and brachial plexus.

\section{CLINICAL SUMMARY}

A 31-year-old African-American man presented with a 1year history of increasing shoulder pain and right forearm paresthesias. He denied any upper limb weakness, weight loss, fever, or dyspnea. Clinical examination revealed 


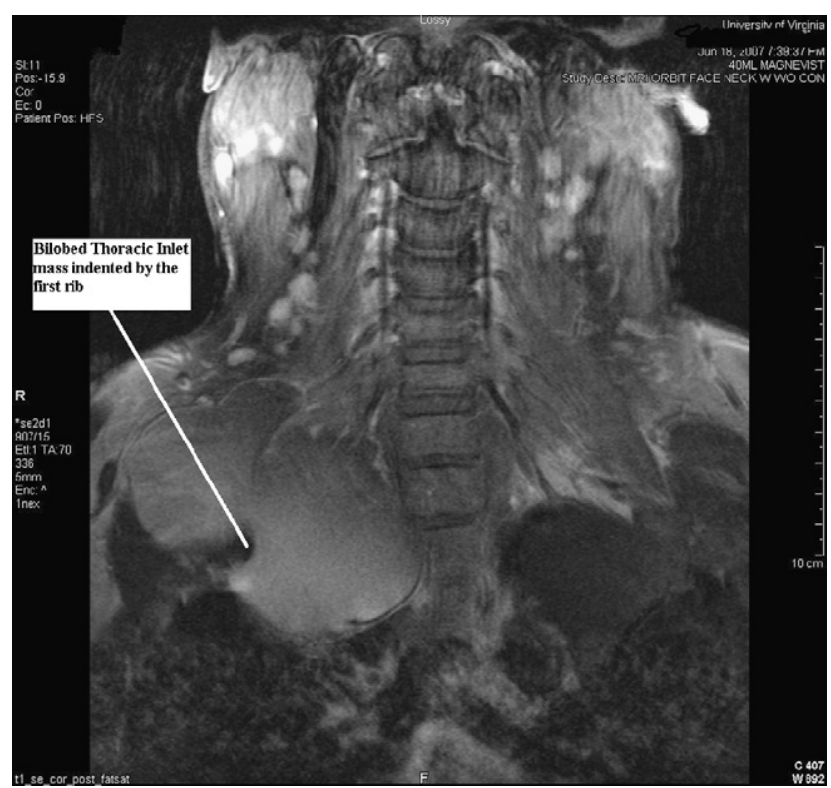

FIGURE 1. MRI scan of bilobed thoracic outlet mass.

a firm, nontender mass in the right supraclavicular fossa without lymphadenopathy. Upper limb strength was normal, but the right radial pulse was not palpable.

Magnetic resonance imaging (MRI) revealed a $4.7 \times 5.6$ $\times 9.8-\mathrm{cm}$ dumbbell-shaped thoracic outlet mass extending from the neck to the posterior right hemithorax (Figure 1). The right subclavian artery was occluded over a 3-cm segment, with reconstitution via collaterals distally. The brachial plexus was compressed, but there was no extension of the lesion inside the neural foramina. The mass was thinly septated with a homogenous high signal, consistent with a lipoma or liposarcoma. Ultrasound-guided core needle biopsies showed no sarcomatous features.

Surgical resection was recommended for severe compressive symptoms and inability to exclude malignancy. Epidural analgesia, double-lumen endotracheal intubation, right arm somatosensory evoked potentials, and free running electromyelogram were monitored during the procedure.

A supraclavicular transverse incision was made, the scalene fat pad was dissected, and the phrenic nerve was protected. After scalenus anterior division, the lesion was visualized tenting up the cords of the brachial plexus. It was dissected using bipolar electrocautery. After complete cervical mobilization of the mass, the incision was extended to a full hemiclamshell approach via the third intercostal space. The mass was divided into 2 lobes by the first rib. The subclavian artery and vein were mobilized from the superior aspect of the first rib, which was then resected subperiosteally. The totally dissected tumour was removed en bloc inferiorly via the third interspace; the brachial plexus prevented its delivery supraclavicularly (Figure 2). The hemi-

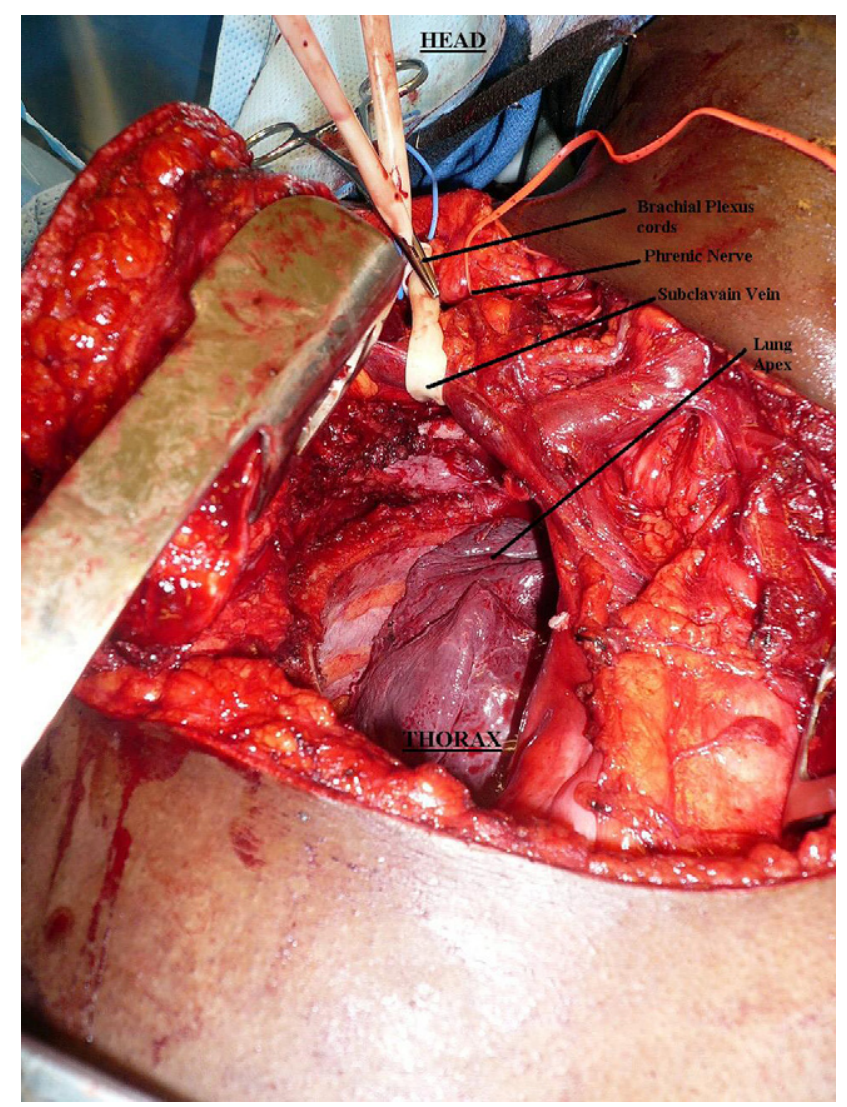

FIGURE 2. Intraoperative hemiclamshell trapdoor incision after lipoma resection.

thorax was drained with thoracostomy tubes, and the incision was closed.

Histopathology revealed a $140-\mathrm{g}, 10 \times 8 \times 4.5-\mathrm{cm}$ benign lipomatous tumor. The patient recovered quickly and was discharged on postoperative day 4 . He had a normal right radial pulse and immediate improvement of his preoperative shoulder pain. One month postoperatively, he had normal strength and sensation in his right arm but continued to have a mild residual right eye ptosis.

\section{DISCUSSION}

Thoracic outlet lesions usually present as an enlarging neck mass or with nondescript upper limb or shoulder pain. They may also present with brachial plexus compressive symptoms, venous thrombosis, or rarely arterial insufficiency. ${ }^{1}$ Lipomas are usually distributed haphazardly. However, there may be a symmetric distribution (Madelung's neck) or associated pain (lipoma dolorosa). A lipoma typically grows by simple expansion. Tissue infiltration is more characteristic of liposarcomas. Despite lipomas being benign tumors, surgical excision may be challenging because of their anatomic location. Computed tomography and MRI are the best modalities to demarcate the lesions' 
anatomic boundaries. MRI is especially useful for evaluating the brachial plexus and excluding neural foramina extension.

There are several surgical approaches for thoracic outlet pathology. These include supraclavicular, transaxillary, and posterior thoracoplasty for first rib excision in thoracic outlet syndrome. For Pancoast tumors, an anterior (Dartevelle), posterior (Shaw-Paulson), and hemiclamshell or Masaoka approach have been described. ${ }^{1-3}$ The Masaoka approach involves a transverse cervical collar incision and proximal median sternotomy extended to the third or fourth anterior intercostal space. We used this approach, and it provided excellent exposure. We resected the first rib subperiosteally from inside the chest, as described by Nomori and colleagues. ${ }^{4}$ This improves exposure by facilitating lateral retraction of the anterior chest wall flap and avoids the need to divide or resect the medial third of the clavicle, which can lead to postoperative shoulder girdle dysfunction. Vanakesa and Goldstraw ${ }^{5}$ reported that the anterosuperior approach provides excellent exposure for tumors at the base of the neck. It was associated with low morbidity, a short postoperative stay, and adequate exposure for subclavian vessel resection or reconstruction.

\section{CONCLUSIONS}

We present the resection of a large bilobed thoracic outlet mass. We recommend an anterior hemiclamshell surgical approach because it provides excellent exposure for tumor removal, first rib resection, and vascular reconstruction. Bipolar electrocautery is essential to avoid any iatrogenic neuropraxias when dissecting the brachial plexus or should any bleeding be encountered around the neural foramina. Monitored somatosensory evoked potentials and free running electromyelogram similarly decrease the risk of neurologic injury.

\section{References}

1. Ducic Y, Crepeau A, Ducic L, Lamothe A, Corsten M. A logical approach to the thoracic inlet: the Dartevelle approach revisited. Head Neck. 1999;21:767-71.

2. Shaw RR. Pancoast's tumor. Ann Thorac Surg. 1984;37:343-5.

3. Masaoka A, Ito Y, Yasumitsu Y. Anterior approach for tumors of the superior sulcus. J Thorac Cardiovasc Surg. 1979;78:413.

4. Nomori H, Nara S, Horio H. Modified trap-door thoracotomy for malignancies invading the subclavian and inominate vessels. J Thorac Cardiovasc Surg. 1995;43:204-7.

5. Vanakesa T, Goldstraw P. Antero-superior approaches in the practice of thoracic surgery. Eur J Cardiothorac Surg. 1999;15:774-80.

\section{Repair of acute postinfarction atrioventricular dehiscence in a patient with posterior left ventricular aneurysm}

Igor E. Konstantinov, MD, PhD, Pankaj Saxena, MCh, DNB, Shane Ling, MB, BS, and Trenton Barrett, MB, BS, Perth, Australia

Acute postinfarction atrioventricular (AV) dehiscence is a rare complication. If the dehiscence is contained, it may form a pseudoaneurysm. The pseudoaneurysm has little strength and is prone to rupture. Left ventricular (LV) pseudoaneurysm is most commonly located at the posterior basal segment, where it is likely to be contained. Repair of postinfarction LV pseudoaneurysm is associated with $20 \%$ to $35.7 \%$ mortality even in the modern era. ${ }^{1-3} \mathrm{We}$ can report the successful management of an acute postin-

\footnotetext{
From the Department of Cardiothoracic Surgery, Sir Charles Gairdner Hospital, University of Western Australia, Perth, Australia.

Received for publication Jan 26, 2008; revisions received Feb 13, 2008; accepted for publication Feb 23, 2008.

Address for reprints: Igor E. Konstantinov, MD, PhD, Department of Cardiothoracic Surgery, Sir Charles Gairdner Hospital, Perth, WA 6009, Australia (E-mail:

konstantinov.igor@alumni.mayo.edu).

J Thorac Cardiovasc Surg 2009;137:247-9

$0022-5223 / \$ 36.00$

Copyright (C) 2009 by The American Association for Thoracic Surgery

doi:10.1016/j.jtcvs.2008.02.033
}

farction $\mathrm{AV}$ dehiscence in a patient with a true posterior $\mathrm{LV}$ aneurysm and severe mitral insufficiency.

\section{CLINICAL SUMMARY}

A 57-year-old diabetic woman had a non-ST elevation myocardial infarction and pulmonary edema. Echocardiography demonstrated severe mitral insufficiency resulting from tethering of the posterior leaflet at P2 and P3 segments, LV ejection fraction of $34 \%$, a true posterior LV aneurysm, and severe calcification of the posterior mitral annulus with an AV dehiscence and a pseudoaneurysm. Magnetic resonance imaging confirmed the findings and delineated an $\mathrm{AV}$ dehiscence of $5 \mathrm{~mm}$ in diameter that formed an entry into a pseudoaneurysm (Figure 1, A) dissecting into the AV groove. The pseudoaneurysm was $22 \times 18 \mathrm{~mm}$ and was contained by coronary sinus and epicardial fat (Figure 1, A and B). A coronary angiogram demonstrated triple-vessel coronary artery disease. An intra-aortic balloon pump was placed before urgent surgery. After median sternotomy, 